\title{
Coarse-grained and all-atom MD simulations with Gromacs based on CELLmicrocosmos 2.2 model membranes
}

\author{
B Sommer ${ }^{1 *}$, T Dingersen ${ }^{1}$, C Gamroth ${ }^{1}$, AJ Heissmann ${ }^{1}$, G Lukat ${ }^{1}$, R Rotzoll ${ }^{1}$, S Rubert ${ }^{1}$, A Schäfer ${ }^{1}$, J Krüger $^{2}$ \\ From 6th German Conference on Chemoinformatics, GCC 2010 \\ Goslar, Germany. 7-9 November 2010
}

The CELLmicrocosmos MembraneEditor (CmME) [1] enables researchers to generate PDB [2] based membrane structures in a convenient way. The lipid distribution is computed by algorithms working on the outer shapes of the molecules. For this reason, the computation and visualization process is very fast, while the atomistic structure of each single molecule remains unchanged.

PDB membranes can be exported to Gromacs [3], a molecular dynamic simulation (MD) program. In this new approach the workflow between CmME and Gromacs has been improved. Two major strategies for the simulation of membranes are the all atom (AA) and coarse-grained (CG) approach. As a logical consequence of the shape-based principle of CmME, coarse-grained support has been implemented. The ongoing work is presented by comparing AA and CG structures generated with CmME, simulated with Gromacs and reverseparsed to CmME.

Newly implemented features of the CmME MD Edition:

- The Membrane Shifter Tool, enabling membrane model repositioning

- Shape generation taking periodic boundaries into account

- A Molecule Editor, supporting the definition of CG particles

- Advanced raft support, allowing the analysis of lipid values and raft-restricted computation of lipid distributions.

\footnotetext{
* Correspondence: bjoern@CELLmicrocosmos.org

'Bio-/Medical Informatics Department, Bielefeld University, 33615 Bielefeld, Germany
}

Full list of author information is available at the end of the article
In addition, a GUI based on the CmME algorithm interface is being implemented, allowing the comfortable handling of CmME and Gromacs based workflows.

\section{Author details}

'Bio-/Medical Informatics Department, Bielefeld University, 33615 Bielefeld, Germany. ${ }^{2}$ Department of Chemistry, University of Paderborn, 33098

Paderborn, Germany.

Published: 19 April 2011

\section{References}

1. Sommer B: Membranen für alle. Nachrichten aus der Chemie 2010, 10:1030-1032, http://Cm2.CELLmicrocosmos.org.

2. Berman HM, Westbrook J, Feng Z, Gilliland G, Bhat TN, Weissig H, Shindyalov IN, Bourne PE: The Protein Data Bank. Nucleic Acids Res 2000, 28:235-242.

3. Hess B, Kutzner C, van der Spoel D, Lindahl E: GROMACS 4: Algorithms for Highly Efficient, Load-Balanced, and Scalable Molecular Simulation. J Chem Theory Comput 2008, 4:435-347.

\section{doi:10.1186/1758-2946-3-S1-P43}

Cite this article as: Sommer et al:: Coarse-grained and all-atom MD simulations with Gromacs based on CELLmicrocosmos 2.2 model membranes. Journal of Cheminformatics 2011 3(Suppl 1):P43.

\section{Publish with ChemistryCentral and every scientist can read your work free of charge \\ "Open access provides opportunities to our colleagues in other parts of the globe, by allowing anyone to view the content free of charge." \\ W. Jeffery Hurst, The Hershey Company. \\ - available free of charge to the entire scientific community \\ - peer reviewed and published immediately upon acceptance \\ - cited in PubMed and archived on PubMed Central \\ - yours - you keep the copyright \\ Submit your manuscript here: \\ http://www.chemistrycentral.com/manuscript/

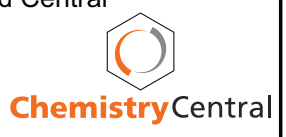

